Revista Brasileira de Agricultura Irrigada v.14, $\mathrm{n}^{\mathrm{o}} .1$, p. 3803 - 3815, 2020

ISSN 1982-7679 (On-line)

Fortaleza, CE, INOVAGRI - http://www.inovagri.org.br

DOI: $10.7127 /$ rbai.v14n1001017

Protocolo 1017.20 - 20/12/2020 Aprovado em 30/03/2020

\title{
DETERMINAÇÃO DA ÁREA DE CLADÓDIOS E FATOR DE CORREÇÃO DA PALMA FORRAGEIRA SOB FERTIRRIGAÇÃO NITROGENADA
}

\author{
Antônio Suassuna de Lima ${ }^{1}$, Patrícia Ferreira da Silva², Rigoberto Moreira de Matos ${ }^{3}$, Semako \\ Ibrahim Bonou ${ }^{4}$, José Dantas Neto ${ }^{5}$
}

\begin{abstract}
RESUMO
A mensuração da área do cladódio é um importante fator requerido em estudos agronômicos para avaliar o crescimento e aprodução de massa verde da palma forrageira. Objetivou-se com este estudo determinar a área de cladódio e o fator de correção de três cultivares de palma forrageira, por diferentes métodos, sob fertirrigação nitrogenada. O experimento foi conduzido em condições de campo na fazenda Poço Redondo, município de Santa Luzia, Paraíba. O delineamento estatístico em blocos casualizados e esquema fatorial $2 \times 2 \times 3$, sendo duas lâminas de irrigação (100 e $25 \%$ da ETo), dois níveis de adubação nitrogenada $\left(0\right.$ e $\left.600 \mathrm{~kg} \mathrm{ha}^{-1} \mathrm{de} N\right)$ e três cultivares de palma forrageira (Orelha de Elefante Mexicana, IPA-Sertânia e Miúda), com cinco repetições.Utilizaram-se os métodos daárea da massa verde, área pelo peso do papel e área em quadrículas. O método da área pelo peso do papel e da área em quadrículas foram os que melhor se ajustaram na determinação da área do cladódio. Sugere-se a utilização do fator de correção médio $\mathrm{F}=0,70$ para a cultivar Orelha de Elefante e 0,75 para IPA-Sertânia e Miúda. As medidas lineares comprimento e largura de cladódios são eficientes na determinação da área do cladódio de palma forrageira com uso de equações lineares de primeira ordem. A lâmina de irrigação de $100 \%$ da $\mathrm{ET}_{0}$ associada à dose de nitrogênio de $600 \mathrm{~kg} \mathrm{ha}^{-1}$ proporcionaram as maiores áreas de cladódios da palma forrageira.
\end{abstract}

Palavras-chave: Opuntia ficus-indica, Nopaleacochenillifera, medidas lineares, ureia.

\section{DETERMINATION OF THE CLADODE AREA AND CORRECTION FACTOR OF THE FORAGE PALM UNDER NITROGEN FERTIRRIGATION}

\footnotetext{
${ }^{1}$ Doutor em Engenharia Agrícola, Universidade Federal de Campina Grande, Campina Grande, PB. E-mail: suassunaagro@gmail.com

${ }^{2}$ Pós Doutoranda em Recursos Naturais, Universidade Federal de Campina Grande, Campina Grande, PB. Email:patrycyafs@yahoo.com.br

${ }^{3}$ Doutorando em Engenharia Agrícola, Universidade Federal de Campina Grande, Campina Grande, PB. Email:rigobertomoreira@gmail.com

${ }^{4}$ Mestrando em Engenharia Agrícola, Universidade Federal de Campina Grande, Campina Grande, PB. E-mail: bonouibrahim@gmail.com

${ }^{5}$ Professor Titular da Unidade Acadêmica de Engenharia Agrícola, Universidade Federal de Campina Grande, Campina Grande, PB. E-mail: zedantas1955@gmail.com
} 


\begin{abstract}
The measurement of the cladode area is an important factor required in agronomic studies to evaluate the growth and production of green mass of forage palm. The objective of this study was to determine the cladode area and the correction factor of three forage palm cultivars, by different methods, under nitrogen fertirrigation. The experiment was conducted under field conditions at the Poço Redondo farm, in the municipality of Santa Luzia, Paraíba. A randomized complete block design and $2 \times 2 \times 3$ factorial scheme, two irrigation slides (100 and $25 \% \mathrm{ET}_{0}$ ), two levels of nitrogen fertilization ( 0 and $600 \mathrm{~kg} \mathrm{ha}^{-1}$ of $\left.\mathrm{N}\right)$ and three cultivars forage palm Orelha de Elefante Mexicana, IPA-Sertânia and Miúda), with five replicates. The methods of the area of the green mass, area by the weight of the paper and area in squares were used. The area method by paper weight and grid area was the ones that best fit the determination of the cladode area. It is suggested the use of the mean correction factor $\mathrm{F}=0.70$ for the Orelha de Elefante Mexicana and 0.75 for IPA-Sertânia and Miúda. The linear length and width measurements of cladodes are efficient in determining the forage palm cladode area using first order linear equations. The $100 \% \mathrm{ET}_{0}$ irrigation depth associated with the nitrogen dose of $600 \mathrm{~kg} \mathrm{ha}^{-1}$ provided the largest areas of cladodes of the forage palm.
\end{abstract}

Keywords: Opuntiaficus-indica, Nopaleacochenillifera, linear measurements, urea.

\section{INTRODUÇÃO}

No Semiárido do Brasil, uma das atividades socioeconômicas mais praticadas é a pecuária, com destaque para a criação de ruminantes. A irregularidade na disponibilidade de alimentos, assim como na distribuição das chuvas e as elevadas taxas de evapotranspiração, visivelmente contribui para o baixo desempenho da pecuária na região (SALES et al., 2013).

Este baixo desempenho da pecuária pode ser mitigado se os produtores utilizarem a palma forrageira como fonte de alimentação para seus rebanhos, visto que essa cactácea surgiu como alternativa para o suprimento da alimentação dos rebanhos no semiárido do Brasil (OLIVEIRA et al., 2010). A mesma pertence ao grupo de plantas que apresenta o denominado metabolismo ácido das crassuláceas (plantas CAM), com abertura dos estômatos principalmente a noite, as quais são capazes de suportar condições climáticas adversas como baixos índices de precipitações e altas temperaturas (PINHEIRO et al., 2014).

Atualmente o Brasil é o país com maior cultivo da palma forrageira, com área plantada estimada em 600 mil ha (SEBRAE, 2010)com produtividade em torno de $600 \mathrm{t}$ de massa verde ha $^{-1}$ ano $^{-1}$, quando produzida com tecnologia de manejo de irrigação e adubação
(MARQUES et al., 2017). A região Nordeste destaca-se no cenário nacional com o cultivo dos gêneros Opuntia e Nopalea, as quais apresentam resistência à cochonilha do carmim (SILVA et al., 2016; DANTAS et al., 2017), uma das principais pragas desta cultura.

$\mathrm{Na}$ planta de palma o cladódio é utilizado no processo de capitação da radiação solar (OLIVEIRA et al., 2007), característica que depende da diferenciação morfológica da cultivar como emissão, tamanho, formato e distribuição dos cladódios. Essa especificação pode influir diretamente na capacidade fotossintetizante e rendimento da cultura (SILVA et al., 2010).

Dubeux Junior et al. (2006) observaram variação na produtividade da palma forrageira em razão do índice de área do cladódio. Resultados semelhantes também foram obtidos por Silva et al. (2010), em pesquisa para determinar a influência das características morfológicas na produção desta cactácea.

A utilização da correlação de Pearson, associando as características morfológicas e produtivas de clones de palma-forrageira é uma forma de identificar a influência que o cladódio exerce sobre a área da palma e também os seus efeitos sobre a produtividade da planta (SILVA et al., 2010; NEDER et al., 2013). A correlação entre características morfológicas e o rendimento da planta 
possibilita compreender a resposta da palma às circunstâncias do ambiente de cultivo.

Apesar do crescente número de pesquisas com palma forrageira, ainda existe um déficit de informações na literatura quanto a esta cactácea. Neste contexto, objetivou-se por meio deste estudo, determinar a área de cladódio e o fator de correção de três cultivares de palma forrageira por diferentes métodos sob fertirrigação nitrogenada.

\section{MATERIAL E MÉTODOS}

O experimento foi conduzido em condições de campo na Fazenda Poço Redondo, munícipio de Santa Luzia, Paraíba, entre maio de 2016 e maio de 2017. O município encontra-se localizado na Microrregião do Seridó Ocidental paraibano com as coordenadas geográficas $06^{\circ} 52^{\prime}$ $27^{\prime \prime}$ de Latitude S, $36^{\circ} 56^{\prime}$ '00' de Longitude W e altitude média de $299 \mathrm{~m}$.

A região encontra-se inserida na Mesorregião da Borborema. O clima local é do tipo Bsh-Tropical, quente seco, semiárido com chuvas de verão (KÖPPEN e GEIGER, 1928).

$\mathrm{O}$ solo da área experimental é classificado como do tipo Neossolos Flúvicos, com textura franco-arenosa (EMBRAPA, 2013) e as características físicas químicas na profundida de de $0-20 \mathrm{~cm}$, encontram-se na Tabela 1.

Tabela 1. Características físicas e químicas do solo utilizado no experimento.

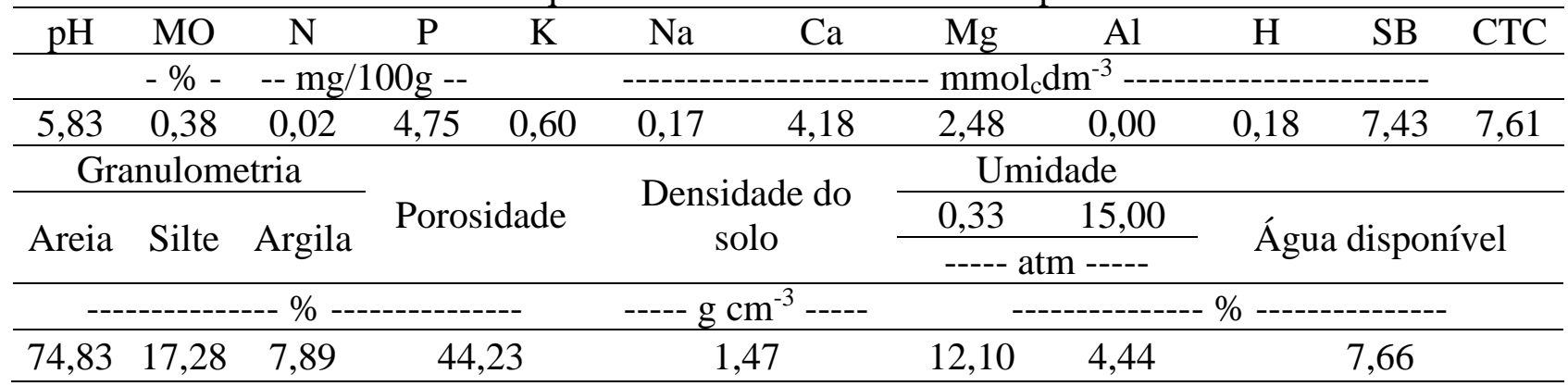

*pH = potencial hidrogeniônico, $\mathrm{MO}=$ matéria orgânica, $\mathrm{N}=$ nitrogênio, $\mathrm{P}=$ fósforo, $\mathrm{K}=$ potássio, $\mathrm{Na}=$ sódio, $\mathrm{Ca}=$ cálcio, $\mathrm{Mg}=$ magnésio, $\mathrm{Al}=$ alumínio, $\mathrm{H}=$ hidrogênio, $\mathrm{SB}=$ soma de bases e $\mathrm{CTC}=$ capacidade de troca de cátions .

O delineamento experimental adotado foi em blocos casualizados, em um esquema fatorial $2 \times 2 \times 3$, constituído de duas lâminas de irrigação $\left(\mathrm{L} 1=100\right.$ e L2 $=25 \%$ da $\left.\mathrm{ET}_{0}\right)$, dois níveis de adubação nitrogenada $(\mathrm{N} 1=0$ e $\mathrm{N} 2=600 \mathrm{~kg} \mathrm{ha}^{-1}$ de $\mathrm{N}$, aplicados via fertirrigação) e três cultivares de palma forrageira [Orelha de Elefante Mexicana (OEM) (Opuntiaficus-indica L. Mill), IPASertânia (IPA) (NopaleacochenilliferaSalm Dyck) e Miúda (MIU) (NopaleacochenilliferaSalm - Dyck), escolhidas por serem resistência a cochonilha do carmim e mais difundidas na região]. Foram utilizadas cinco repetições por tratamento, totalizando 60 unidades experimentais.

As parcelas foram constituídas de uma fileira dupla de plantas com espaçamento de
0,25 $\mathrm{m}$ entre plantas, $0,4 \mathrm{~m}$ entre linhas e 2,0 $\mathrm{m}$ entre fileiras duplas; com $5,0 \mathrm{~m}$ de comprimento e 1,0 m de bordadura. As plantas da bordadura foram desprezadas, sendo consideradas para análises somente as plantas centrais, localizadas na área útil da parcela.

Aplicou-se $200 \mathrm{~kg} \mathrm{ha}^{-1}$ de Fosfato Monoamónico- MAP (52\% de $\left.\mathrm{P}_{2} \mathrm{O}_{5}\right)$, como fonte de fósforo, na adubação de fundação. Para o potássio a fonte foi o cloreto de potássio $\left(60 \%\right.$ de $\left.\mathrm{K}_{2} \mathrm{O}\right)$, aplicando-se $108,3 \mathrm{~kg}$ $\mathrm{ha}^{-1}$. Essa mesma quantidade foi aplicada em todas as parcelas na implantação da cultura, seguindo as recomendações de Santos et al. (2006) e de acordo com a análise do solo. A fonte de nitrogênio utilizada foi a ureia ( $45 \%$ de $\mathrm{N}$ ), correspondendo a 0 e $105,5 \mathrm{~kg}$ de ureia aplicada via fertirrigação, parcelada a cada 30 dias. Na adubação orgânica, aplicou-se 
aproximadamente $1,0 \mathrm{Kg}$ de esterco bovino por metro linear.

O plantio dos cladódios foi em sulcos com alinhamento bilateral (tipo Dominó) (SUASSUNA, 1993). O material foi submetido ao período de cura à sombra durante sete dias, quando o cladódio perde umidade, tornando possível observar a perda de turgidez. Esse intervalo de tempo também serve para que ocorra a cicatrização das lesões provocadas no cladódio pela operação de corte no campo.

A água para irrigação foi pressurizada de um poço amazonas localizado a $80 \mathrm{~m}$ da área da pesquisa por meio de uma motobomba centrífuga de 3,0 CV. Foi adotado o sistema de irrigação localizado por gotejamento, constituído por fitas gotejadoras com espessura da parede de $0,2 \mathrm{~mm}$, diâmetro interno de $16 \mathrm{~mm}$ e espaçamento entre gotejadores de $0,20 \mathrm{~m}$.

A lâmina liquida de irrigação (La) aplicada em cada tratamento foi determinada levando em consideração a evapotranspiração de referência para os tratamentos correspondentes a 25 e $100 \%$ da $\mathrm{ET}_{0}$ (Equação 01).

$$
\mathrm{La}=\left(\mathrm{ET}_{0} * \mathrm{LAP}\right)-\mathrm{P}
$$

Em que: La - Lâmina a ser aplicada em cada tratamento, mm; $\mathrm{ET}_{0}$ - Evapotranspiração de referência, mm; LAP - Fração da lâmina aplicada em cada parcela, em decimal; P Precipitação no período, $\mathrm{mm}$.

Para determinar a área do cladódio (AC) da palma forrageira, foram utilizados três diferentes métodos, o método de área da massa verde do cladódio (Amv), o método da área pelo peso do papel(App) e o método de área em quadrículas (Aqu) (SOUZA et al., 2012).

O método de área da massa verde (Amv) foi obtido com a pesagem de 30 cladódios, retirando-se, em seguida, cinco discos com diâmetro de $2 \mathrm{~cm}$ em cada cladódio e pesandoos para determinar-se a área da amostra, com uma regra de três simples (Equação 02).

$\mathrm{Amv}=\left(\mathrm{Mvc} * \pi \mathrm{r}^{2}\right) / \mathrm{Mvd}$
Em que: Amv - Área da massa verde, em $\mathrm{cm}^{2} ;$ Mvc - Massa verde do cladódio, em g; $\mathrm{r}$ Raio do disco do cladódio, em cm; Mvd Massa verde dos discos, em g.

O método da área pelo peso do papel (App) delimitou-se ao contornar a área do cladódio da palma em uma folha de papel em branco, foram utilizados 30 cladódios. Depois da área contornada foi recortada e pesada com o auxilio de uma balança de precisão $(0,001 \mathrm{~g})$. Posteriormente, traçou-se um retângulo da área conhecida no papel, em seguida esta foi cortada e pesada. Com os pesos obtidos fez-se a substituição em regra de três simples para se determinar a área dos cladódios (Equação 03).

$\mathrm{App}=(\mathrm{Pdc} * \mathrm{At}) / \mathrm{Pt}$

Em que: App - Área pelo peso do papel, em $\mathrm{cm}^{2}$; Pdc - Peso do desenho do cladódio, em g; At - Área do retângulo, $\mathrm{cm}^{2} ; \mathrm{Pt}$ - Peso do retângulo, em g.

O método da área em quadrículas (Aqu) consistiu em pegar um papel cartolina de cor brancacom dimensões de 50 x $66 \mathrm{~cm}$ e $180 \mathrm{~g}$, dividir a folha em áreas conhecidas de $4 \mathrm{~cm}^{2}$ (2 $\mathrm{cm}$ de comprimento $\times 2 \mathrm{~cm}$ de largura), depois colocar o cladódio da palma (utilizouse 30 cladódios) sobre o papel quadriculado e, com uma caneta, desenhar o seu contorno. Para estimar a área do cladódio, multiplicou-se o número de quadrículas dentro do contorno, pela constante $4 \mathrm{~cm}^{2}$.

O fator de correção foi determinado em função da forma do cladódio, conforme equação 04, com base no método área pelo peso do papel (App).

$\mathrm{F}=\frac{\mathrm{App}}{\mathrm{CC} * \mathrm{LC}}$

Em que: F - Fator de correção, adimensional; App - Área do papel, em $\mathrm{cm}^{2}$; $\mathrm{CC}$ - Comprimento do cladódio, em cm; CL Largura do cladódio, $\mathrm{cm}$.

De posse do fator de correção obteve-se a equação de $1^{\circ}$ grau para determinar a área do cladódio da palma forrageira (AC) em $\mathrm{cm}^{2}$ (Equação 05), com base na área pelo peso do papel (App), pois este é considerado como 
um método de referência para determinação da área de cladódio (PINHEIRO et al., 2014).

$A C=C C * L C * F$

Em que: AC - Área do cladódio, em $\mathrm{cm}^{2} ; \mathrm{CC}$ - Comprimento do cladódio, em cm; CL - Largura do cladódio, em cm; F - Fator de correção, adimensional.

Foram avaliadas as relações das características morfológicas como área, comprimento e largura dos cladódios para o método que melhor estimou a área do cladódio. Para isto, efetuou-se a correlação de Pearson (r) entre as variáveis estudadas. Com a aplicação de correlações lineares, finalmente estipulou-se qual a relação existente entre a área do cladódio (AC), o comprimento do cladódio (CC) e a largura do cladódio (LC).

As variáveis foram analisadas estatisticamente por meio de análise de variância simples, desdobrando-se as análises sempre que a interação fosse significativa, quando da significância aplicou-se o teste de Tukey ao nível de 5\%, com auxílio do Sisvar (FERREIRA, 2014).

\section{RESULTADOS E DISCUSSÃO}

Os dados obtidos foram comparados com base na análise de variância e constatou interação entre os fatores (lâmina de irrigação $\mathrm{x}$ doses de nitrogênio) levando em consideração as três cultivares estudadas e os três métodos de determinação analisados. O desdobramento da interação encontra-se na Tabela 2. Em todos os métodos avaliados, as maiores áreas de cladódios foram atingidas nas plantas que receberam $600 \mathrm{~kg} \mathrm{ha}^{-1}$ de $\mathrm{N}$ com $100 \%$ da reposição da evapotranspiração (tratamento N2L1). Com destaque para a cultivar orelha de elefante mexicana (OEM), que apresentou os maiores valores de área de cladódio-AC (Tabela 2).

Tabela 2. Área de cladódio $\left(\mathrm{cm}^{2}\right)$ por planta de palma forrageira, nas cultivares orelha de elefante mexicana (OEM), IPA-Sertânia (IPA) e Miúda (MIU)pelos diferentes métodos de determinação para cada tratamento estudado.

\begin{tabular}{|c|c|c|c|c|c|c|c|c|c|}
\hline \multirow{3}{*}{ Tratamento } & \multicolumn{9}{|c|}{ Cultivar } \\
\hline & \multicolumn{3}{|c|}{ OEM } & \multicolumn{3}{|c|}{ IPA } & \multicolumn{3}{|c|}{ MIU } \\
\hline & Amv & App & $\mathrm{Aqu}$ & Amv & App & $\mathrm{Aqu}$ & Amv & App & $\mathrm{Aqu}$ \\
\hline N1L1 & $3674 b$ & $6743 a$ & $6924 a$ & $854 b$ & $1339 a$ & $1379 a$ & $1411 b$ & $2021 \mathrm{a}$ & $2092 a$ \\
\hline N1L2 & $2615 b$ & $4519 a$ & $4695 a$ & $1472 b$ & $2309 a$ & $2389 a$ & $2324 b$ & $3597 \mathrm{a}$ & $3723 a$ \\
\hline N2L1 & $7476 b$ & $13257 \mathrm{a}$ & $13909 a$ & $5869 b$ & $8835 a$ & $9177 \mathrm{a}$ & $5332 b$ & $8548 \mathrm{a}$ & $8878 \mathrm{a}$ \\
\hline N2L2 & $7185 b$ & $11987 \mathrm{a}$ & $12435 a$ & $3085 b$ & $5592 \mathrm{a}$ & $5720 \mathrm{a}$ & $5031 b$ & $7744 a$ & $8243 a$ \\
\hline
\end{tabular}

Amv = Área da massa verde $\left(\mathrm{cm}^{2}\right) ; \mathrm{App}=$ Área pelo peso do papel $\left(\mathrm{cm}^{2}\right)$; e Aqu = Área em quadriculas.

O método da área pelo peso do papel (App) e da área da quadricula (Aqu) foram os que melhor se ajustaram, na determinação da área de cladódio nas três cultivares, não diferindo estatisticamente entre eles. Em todos os tratamentos o método (Amv) subestimou os valores da área de cladódios (Tabela 2).

Quando se compara os dois melhores métodos de determinação da área do cladódio, nota-se que o método da área em quadrículas (Aqu) é mais laborioso em função da necessidade de dividir a folha em áreas conhecidas, desenhar o contorno do cladódio na folha e fazer a contagem do número de quadrículas.

Pinheiro et al. (2014) relatam que a irregularidade no formato do cladódio e sua espessura variam ao longo do comprimento, afetando diretamente a aplicabilidade dos diferentes métodos de estimativa da área do cladódio, fato que ocorre em função dos cladódios não preencher uniformemente os quadrados, o que resulta em subestimação ou superestimação dos métodos utilizados. 
Resultados estes semelhantes aos observados no presente estudo.

No entanto, alguns autores relatam a necessidade de um fator de correção para ser multiplicado por valores de comprimento e largura estimados por método de medidas lineares, visando superar essa subestimação ou superestimação dos métodos, de forma a buscar sua calibração real (DOMBROSKI et al., 2010).

A área foliar pode ser obtida através de métodos indiretos, em que as medições são realizadas nas folhas por meio de análises planimétrica ou lineares, os quais estimam a área sem necessidade de destruição da planta, contudo vale salientar que as variáveis como comprimento e largura das folhas ou mesmo dos cladódios dependem da espécie, cultivar, do manejo da cultura e das tecnologias adotadas, sejam adubação, irrigação, cultivo adensando, dentre outras (MARCON et al., 2011).

Para estimar-se a área de cada cladódio em campo obtiveram-se equações do primeiro grau com base na equação 5, nesta equação adotou-se para fator de correção a equação 4.A partir da relação entre a área do cladódio, pelo método da área pelo peso do Papel (App) e o produto do comprimento do cladódio pela largura (CC*LC) de cada planta (Tabela 3).

Tabela 3. Equação de primeiro grau com fator de correção com base na equação 4 e 5 , em função do comprimento do cladódio (CC), e da largura do cladódio (LC) para estimar a área do cladódio (AC) nas cultivares orelha de elefante mexicana (OEM), IPA-Sertânia (IPA) e Miúda (MIU) para cada tratamento estudado pelo método do peso do papel (App) de cada planta.

\begin{tabular}{|c|c|c|c|c|c|c|c|c|c|}
\hline \multirow{3}{*}{$\begin{array}{c}\text { Tratamento } \\
\mathrm{s}\end{array}$} & \multicolumn{9}{|c|}{ Cultivar } \\
\hline & \multicolumn{3}{|c|}{ OEM } & \multicolumn{3}{|c|}{ IPA } & \multicolumn{3}{|c|}{ MIU } \\
\hline & App & $\mathrm{C}^{*} \mathrm{~L}$ & $\begin{array}{c}\text { Equação } 1^{\circ} \\
\text { grau }\end{array}$ & App & $\mathrm{C}^{*} \mathrm{~L}$ & $\begin{array}{c}\text { Equação } 1^{\circ} \\
\text { grau }\end{array}$ & App & $\mathrm{C}^{*} \mathrm{~L}$ & $\begin{array}{c}\text { Equação } 1^{\circ} \\
\text { grau }\end{array}$ \\
\hline N1L1 & $\begin{array}{c}449 \\
5\end{array}$ & $\begin{array}{c}645 \\
5\end{array}$ & $\begin{array}{c}\mathrm{CC}^{*} \mathrm{LC}^{*} 0,7 \\
0\end{array}$ & $\begin{array}{c}267 \\
8\end{array}$ & $\begin{array}{c}369 \\
8\end{array}$ & $\begin{array}{c}\mathrm{CC}^{*} \mathrm{LC}^{*} 0,7 \\
4\end{array}$ & $\begin{array}{c}120 \\
8\end{array}$ & $\begin{array}{c}145 \\
3\end{array}$ & $\begin{array}{c}\mathrm{CC}^{*} \mathrm{LC} * 0,8 \\
2\end{array}$ \\
\hline N1L2 & $\begin{array}{c}451, \\
9\end{array}$ & $\begin{array}{c}651 \\
9\end{array}$ & $\begin{array}{c}\mathrm{CC} * \mathrm{LC} * 0,7 \\
0\end{array}$ & $\begin{array}{c}164 \\
9\end{array}$ & $\begin{array}{c}210 \\
3\end{array}$ & $\begin{array}{c}\text { CC*LC*0,7 } \\
9\end{array}$ & $\begin{array}{c}180 \\
0\end{array}$ & $\begin{array}{c}232 \\
5\end{array}$ & $\begin{array}{c}\text { CC*LC*0,7 } \\
9\end{array}$ \\
\hline N2L1 & $\begin{array}{c}395 \\
8\end{array}$ & $\begin{array}{c}597 \\
8\end{array}$ & $\begin{array}{c}\text { CC*LC*0,6 } \\
5\end{array}$ & $\begin{array}{c}267 \\
7\end{array}$ & $\begin{array}{c}364, \\
0\end{array}$ & $\begin{array}{c}\text { CC*LC*0,7 } \\
4\end{array}$ & $\begin{array}{c}122 \\
9\end{array}$ & $\begin{array}{c}180 \\
9\end{array}$ & $\begin{array}{c}\text { CC*LC* } 0,6 \\
8\end{array}$ \\
\hline N2L2 & $\begin{array}{c}386 \\
7\end{array}$ & $\begin{array}{c}536 \\
8\end{array}$ & $\begin{array}{c}\mathrm{CC}^{*} \mathrm{LC}^{*} 0,7 \\
2\end{array}$ & $\begin{array}{c}349 \\
5\end{array}$ & $\begin{array}{c}461 \\
4\end{array}$ & $\begin{array}{c}\mathrm{CC}^{*} \mathrm{LC}^{*} 0,7 \\
5\end{array}$ & $\begin{array}{c}155 \\
5\end{array}$ & $\begin{array}{c}211 \\
0\end{array}$ & $\begin{array}{c}\mathrm{CC} * \mathrm{LC} * 0,7 \\
4\end{array}$ \\
\hline
\end{tabular}

App = Área pelo peso do papel; $\mathrm{CC}=$ Comprimento do cladódio; e LC $=$ Largura do cladódio.

As equações de primeiro grau para os tratamentos foram estimadas a partir da determinação da média total das áreas dos cladódios de cada tratamento pelo método do peso de papel (App), assim como, a média total do produto do comprimento pela largura (CC*LC), posteriormente dividiu-se a média das áreas total pela média do produto (CC*LC) e em seguida determinou-se os fatores para cada equação. Com a obtenção dos fatores para cada tratamento estabeleceuse uma equação geral para cada variedade de palma forrageira estudada, conforme os resultados apresentados na Tabela 3 .

Os fatores de correção determinados em função da forma dos cladódios, variaram entre
$0,65-0,72 ; \quad 0,74-0,79 ; \quad 0,68-0,82$ para as cultivar Orelha de Elefante, IPA Sertânia e Miúda, respectivamente (Tabela 3). Nota-se ainda que o fator de correção para a área do cladódio independe da lâmina de irrigação aplicada e da dose de nitrogênio, no entanto, foi dependente das características inerentes a cada cultivar estudada.

Os valores determinados para o fator de correção das cultivar de palma forrageira estudadas são superiores ao recomendado por Santos et al., (2006) que corresponde a um $\mathrm{F}=0,53$. Este fato esta relacionado à genética das plantas estudadas e ao diferente manejo adotado para a cultura. 
Analisando a Figura 1A, B, C e D que determinam a correlação de Pearson entre a área de cladódios versus o comprimento e largura de cada cladódio para a cultivar orelha de elefante mexicana (OEM) em cada tratamento, verifica-se que os coeficientes de determinação $\left(\mathrm{R}^{2}\right)$ apresentaram uma similaridade entre eles para todos os

(A)

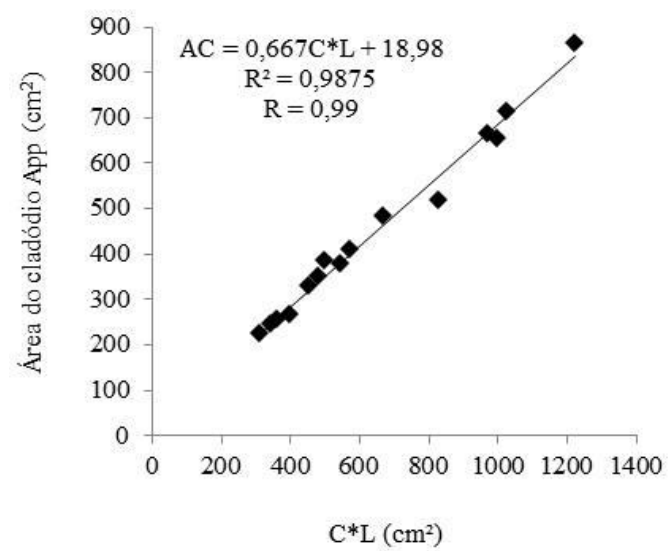

(C)

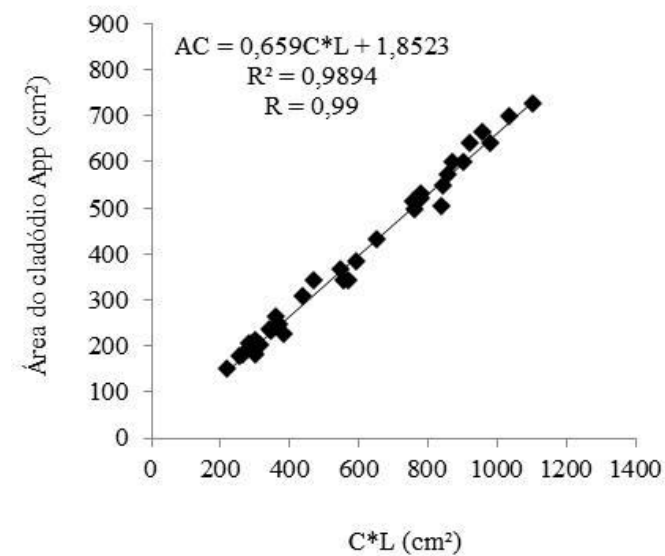

tratamentos, variando de 0,93 a 0,98 . Constatou-se ainda alta correlação de Pearson (R) entre o $(\mathrm{CC} * \mathrm{LC})$ e a área do cladódio pelo método da área do papel (App), com coeficientes de correlação entre 0,96 e 0,99, sendo que á medida em que aumenta o (CC*LC) também se verificou incremento positivo na (AC).

\section{(B)}

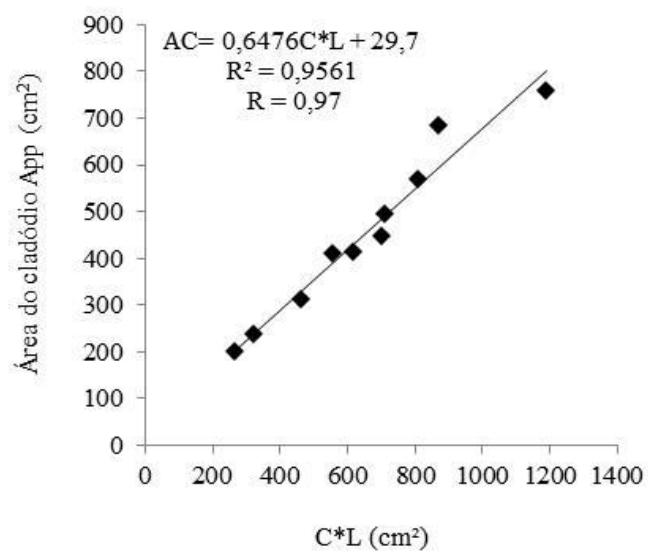

(D)

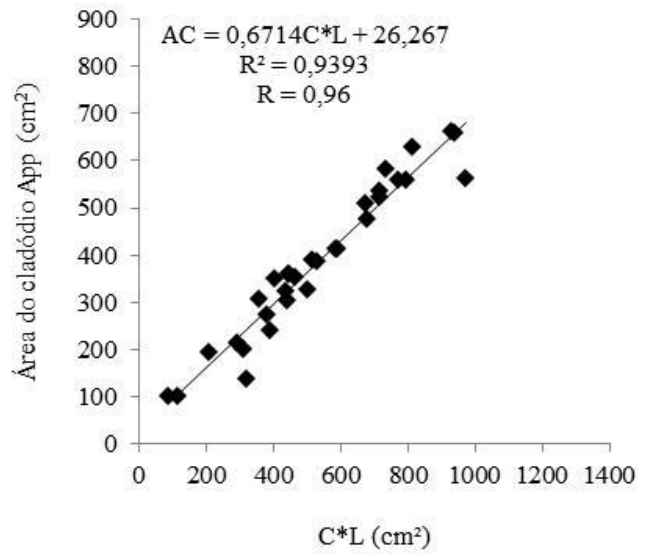

Figura 1. Gráficos de correlação entre $C^{*} \mathrm{~L}$ e área do cladódio pelo método da área do papel (App) para a cultivar Orelha de Elefante: Tratamento N1L1 (A); N1L2 (B); N2L1 (C) e N2L2 (D).

Nota-se ainda que ocorreram pequena dispersão dos dados em relação à reta obtida, indicando que estimativas precisas e relativamente simples podem ser obtidas com a equação linear simples com a reta passando pela origem (Figuras 1A, B, C e D). Resultados semelhantes a estes foram encontrados por Silva et al. (2014) que, fazendo uso da técnica da imagem digital e de modelos matemáticos para determinar a $(\mathrm{AC})$ de clones de palma forrageira, observaram que a cultivar orelha de elefante mexicana
(OEM)apresentou maior AC, quando correlacionada com o comprimento do cladódio - CC e com o perímetro do cladódio PC. Isso evidência que a AC está altamente correlacionada com as variáveis biométricas da palma forrageira.

Pinheiro et al. (2014) observaram correlação positiva das variáveis morfológicas com o índice de área do cladódio (IAC) da cultivar orelha de elefante mexicana (OEM). Os mesmos explicam que essas características representam $63,7 \%$ do comportamento de 
(IAC) desta cultivar. E quando correlacionadas com o rendimento da cultura as variáveis analisadas refletem em $94,3 \%$ de sua variabilidade. Corroborando com estes resultados Neder et al. (2013) encontraram relações de $82,0 \%$ entre a produtividade de acessos de Opuntiaficus-indica e as características morfológicas da mesma.

Silva et al. (2015) comparando o crescimento e a produtividade de três clones de palma, constaram que o maior rendimento de biomassa verde da cultivar orelha de elefante mexicana (OEM) está diretamente associado ao (IAC). Resultados semelhantes foram identificados em estudos que indicam a

\section{(A)}

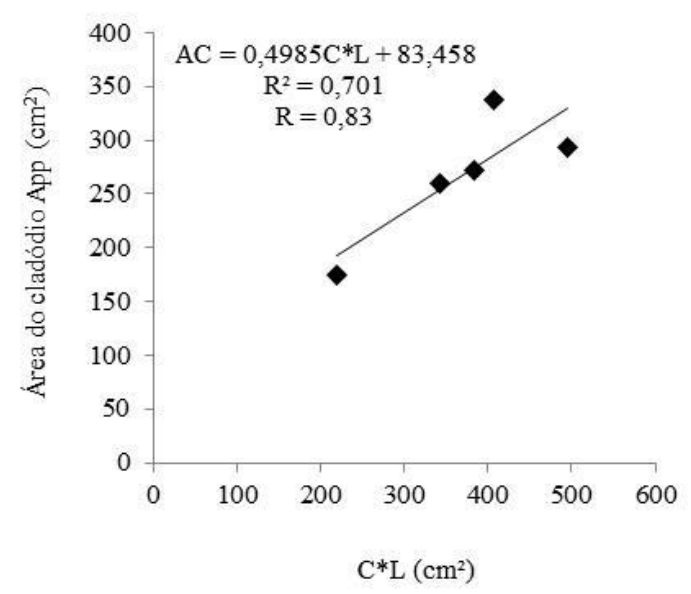

(C)

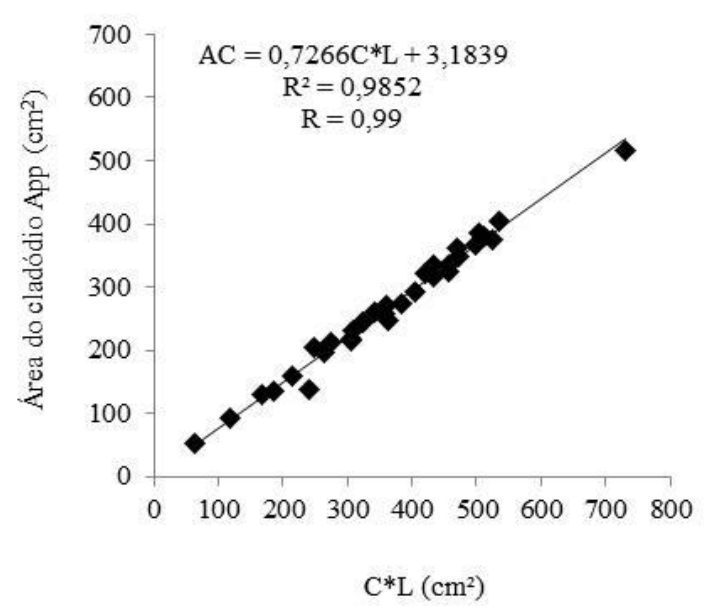

influência do (IAC), em relação à produção de biomassa da Opuntiaficus-indica (SALES et al., 2013). Para Cortázar e Nobel (1991) o crescimento e a máxima produtividade da palma estão intimamente relacionados com a área de cladódios da cultura. Quando se estudou a correlação entre a área de cladódio determinada pelo método do papel e o CC*LC da cultivar IPA Sertânia em cada tratamento, observou-se que, não houve praticamente nenhuma diferença entre os coeficientes de determinação $\left(\mathrm{R}^{2}\right)$ nos diferentes tratamentos, com exceção do tratamento N1L1 que apresentou uma leve inferioridade em relação aos demais (Figura 2A, B, C e D).

(B)

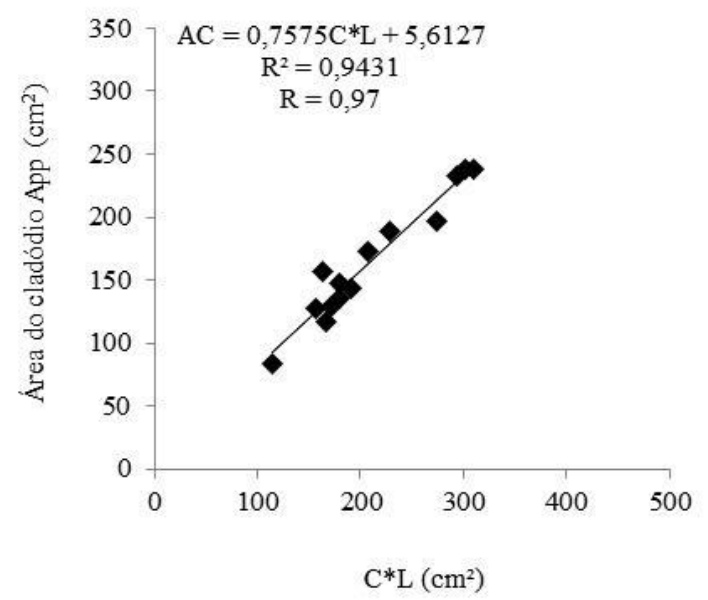

(D)

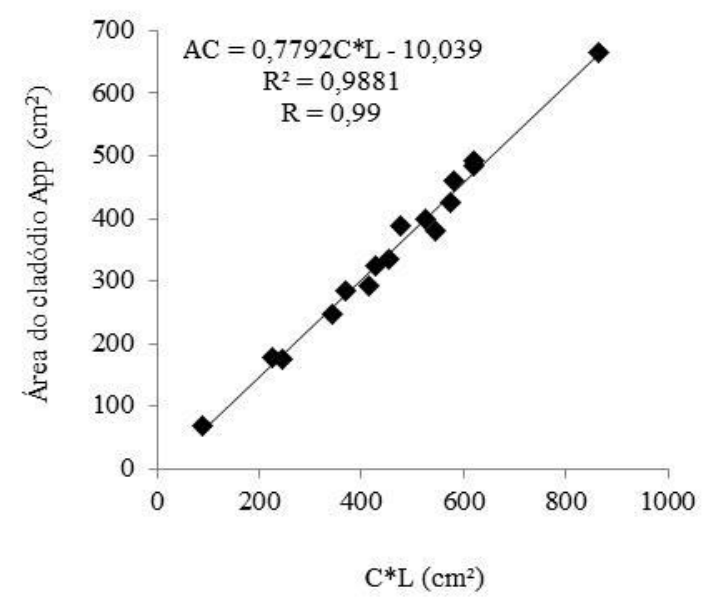

Figura 2. Gráficos de correlação entre $C^{*} \mathrm{~L}$ e área do cladódio pelo método da área do papel (App) para a cultivar IPA-Baiana: Tratamento N1L1 (A); N1L2 (B); N2L1 (C) e N2L2 (D). 


\section{DETERMINAÇÃO DA ÁREA DE CLADÓDIOS E FATOR DE CORREÇÃO DA PALMA FORRAGEIRA SOB FERTIRRIGAÇÃO NITROGENADA}

Também foi verificado que ocorreu alta correlação de Pearson (R) entre o (CC*LC) e a (AC) pelo método (App), sendo que os coeficientes de correlação variaram de 0,83 a 0,99 , no entanto, ao passo que o $(\mathrm{CC} * \mathrm{LC})$ aumentou, houve um acréscimo na (AC). Fato este, que comprova a influência direta das variáveis morfológicas da cultura na determinação da (AC), nas diferentes cultivar estudadas (Figura 2A, B, C e D).

Nota-se ainda que nos tratamentos N2L1 e N2L2 (Figuras 2C e D) tanto as áreas de cladódios pelo método do papel quanto o $\mathrm{CC} * \mathrm{LC}$ foram superiores aos obtidos nos tratamentos N1L1 e N1L2 (Figuras 2A e B). Fato que possivelmente esteja relacionado com o maior fornecimento de nitrogênio aplicado via fertirrigação às plantas.

De acordo com Padilha Junior et al. (2016) a área de cladódio é uma variável que além de depender das características biométricas do cladódio, também pode ser influenciada pela densidade de plantio e principalmente pela condição nutricional da planta. Estes resultados muito se assemelham aos encontrados por Pinheiro et al. (2014) que confirmaram correlações positivas ao analisarem as relações entre características morfológicas e o (IAC) da variedade (IPA). Os autores ainda observaram que as correlações analisadas, influenciaram em $49,5 \%$ da variação do (IAC) e em 59,3\% quanto ao rendimento da cultura.

Dubeux Junior et al. (2006) e Oliveira Junior et al. (2009) observaram que a magnitude do (IAC) de clones de Opuntia e Nopalea, está associado ao número de cladódios (NC), a largura do cladódio (LC), ao comprimento do cladódio (CC) e ao perímetro do cladódio (PC), bem como ao hábito de crescimento da cultura.

Silva et al. (2014) estudando clones da cultivar (IPA) constaram a existência de relação entre as variáveis biométricas do cladódio, a área do cladódio e o índice de área de cladódio (IAC) e destes, com a produtividade em toneladas de matéria verde por hectare, de modo que a evolução dessas características proporcionou um incremento considerável na produtividade.

Na Figura 3A, B, C e D onde estão contidos os valores que estabelece a (AC) da cultivar miúda - MIU correlacionando-se com $\mathrm{CC} * \mathrm{LC}$ em cada tratamento, verifica-se que, assim como nas demais cultivar orelha de elefante mexicana - OEM e IPA - Sertânia IPA os coeficientes de determinação $\left(\mathrm{R}^{2}\right)$ foram bem próximos, obtendo $\left(\mathrm{R}^{2}\right)$ semelhantes em todos os tratamentos, com valores entre 0,80 e 0,96 . 
(A)

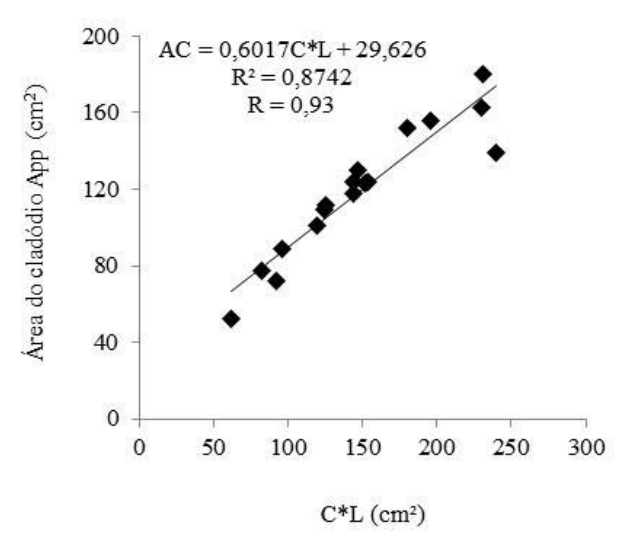

(C)

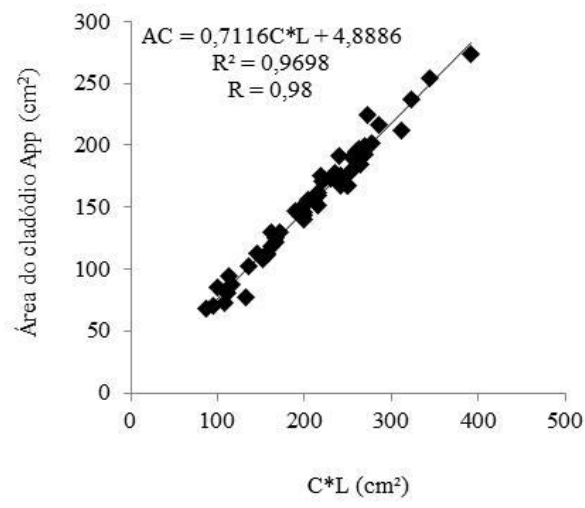

(B)

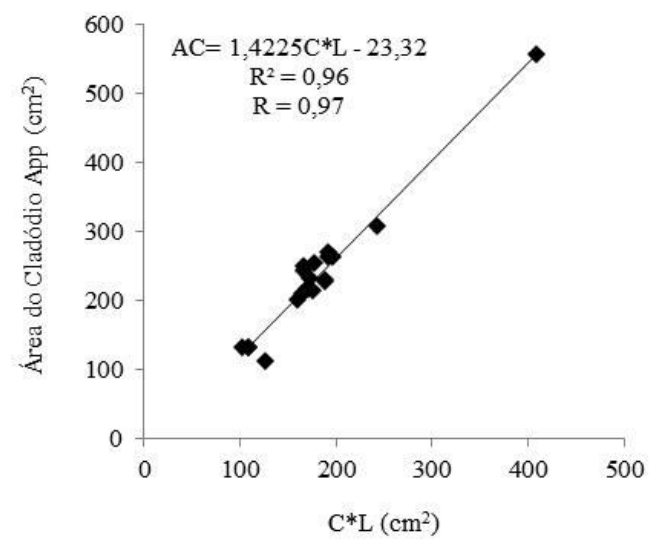

(D)

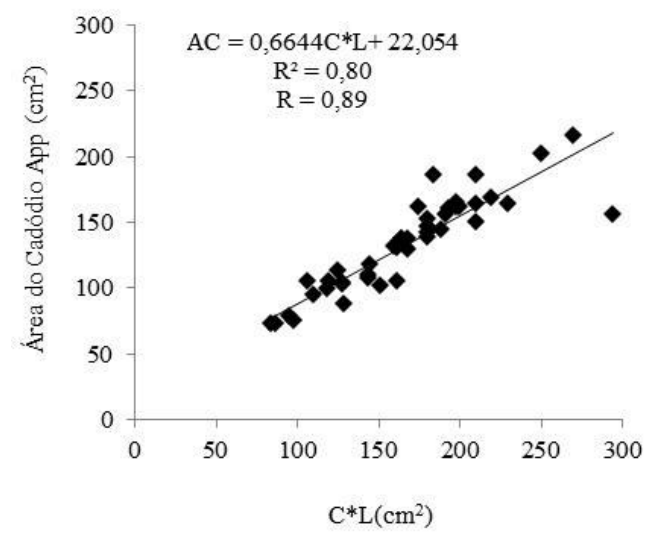

Figura 3. Gráficos de correlação entre C*L e área do cladódio pelo método da área do papel (App) para a cultivar Miúda: Tratamento N1L1 (A); N1L2 (B); N2L1 (C) e N2L2 (D).

Simultaneamente é possível observar que houve alta correlação do (CC*LC) com a AC pelo método App, com os coeficientes de correlação de Pearson obtidos entorno de 0,89 a 0,98 , proporcionando um incremento na $\mathrm{AC}$ da cultivar miúda - MIU conforme o aumento do comprimento do cladódio versus a largura do cladódio (CC*LC) (Figura 3A, B, C e D). As equações apresentaram estimativas do coeficiente de determinação $\left(\mathrm{R}^{2}\right)$ superiores a 0,80 , indicando que a variabilidade total existente na área dos cladódios, mais de $80 \%$, pode ser explicada pela equação de regressão linear (Figura 3A, B, C e D). Corroborando com estes resultados Pinheiro et al. (2014) constataram correlação média das variáveis altura de planta, comprimento e largura do cladódio, número de cladódios e espessura do cladódio, com o IAC da cultivar miúda - MIU. Os mesmos pesquisadores concluíram que essa correlação contribuiu em 29,2\% da variação do índice de área do cladódio.

No entanto, estas correlações justificaram $95,2 \%$ da variação no rendimento da cultivar miúda (MIU). Os resultados da pesquisa diferem dos obtidos por Silva et al. (2014) que revelaram baixa correlação das variáveis morfológicas com a área do cladódio da cultivar Miúda (MIU). Os autores supracitados justificam que a variedade dispõe 
de cladódios pequenos e pouco colaboram para o incremento de sua área. Isso contribui para um menor IAC quando comparado com as cultivar Orelha de Elefante Mexicana (OEM)e IPA-Sertânia (IPA) (SILVA et al., 2015).

Para Rocha et al. (2017) tanto o espaçamento quanto a densidade de plantio podem influenciar no (IAC) da palma forrageira. Segundo Dubeux Junior et al. (2006); Sales et al. (2013) a área do cladódio assim como o IAC da palma pode variar de acordo com a espécie, idade e níveis de adubação, bem como a temperatura e o fornecimento de água a cultura. Peduzziet al. (2012); Zegbe et al. (2014) afirmam que as condições da área de cultivo e o tipo de manejo empregado na cultura, estão diretamente relacionados com a área do cladódio e o índice de área do cladódio da palma forrageira.

\section{CONCLUSÕES}

$\mathrm{O}$ método da área pelo peso do papel e da área em quadrículas foram os que melhor se ajustaram na determinação da área do cladódio, contudo o método da área do papel é mais prático.

Sugere-se a utilização do fator de correção médio $\mathrm{F}=0,70$ para á cultivar Orelha de Elefante Mexicana e 0,75 para IPASertânia e Miúda.

As medidas lineares comprimento $\mathrm{e}$ largura de cladódios são eficientes na determinação da área do cladódio de palma forrageira com uso de equações lineares de primeira ordem.

A lâmina de irrigação de $100 \%$ da $\mathrm{ET}_{0}$ associada à dose de nitrogênio de $600 \mathrm{~kg} \mathrm{ha}^{-1}$ proporcionaram as maiores áreas de cladódios da palma forrageira.

\section{AGRADECIMENTOS}

Ao Conselho Nacional de Desenvolvimento Científico e Tecnológico
$(\mathrm{CNPq})$, pelo apoio financeiro ao projeto e à Coordenação de Aperfeiçoamento de Pessoal de Nível Superior (CAPES), pela concessão de bolsas.

\section{REFERÊNCIAS BIBLIOGRÁFICAS}

CORTÁZAR, V. G.; NOBEL, P. S. Prediction and measurement of high annual productivity for Opuntiaficu-indica.Agricultural and Forest Meteorology, v. 56, n. 3, p. 261-272, 1991.https://doi.org/10.1016/01681923(91)90095-8

DANTAS, S. F. A.; LIMA, G. F. C.; MOTA, E. P. Viabilidade econômica da produção de palma forrageira irrigada e adensada no Semiárido potiguar. Revista iPecege, v. 3, n.1, p. 59-74, 2017. https://doi.org/10.22167/r.ipecege.2017.1.59

DOMBROSKI, J. L. D.; RODRIGUES, G. S. O.; BATISTA, T. M. V.; LOPES, W. A. R.; LUCENA, R. R. M. Análise comparativa de métodos de determinação de área foliar em Pinha (AnnonaSquamosa L.). Revista Verde de Agroecologia e Desenvolvimento Sustentável, v. 5, n. 3, p. 188-194, 2010. https://doi.org/10.18378/rvads.v5i3.322

DUBEUX JUNIOR, J. C. B.; SANTOS, M. V. F. dos; LIRA, M. de. A.; SANTOS, D. C. dos; FARIAS, I.; LIMA, L. E.; FERREIRA, R. L. C. Productivity ofOpuntiaficus-indica (L.) Miller under different $\mathrm{N}$ and $\mathrm{P}$ fertilization and plant population in north-east Brazil. Journal of Arid Environments, v. 67, n. 3, p. 357372, 2006. https://doi.org/10.1016/ j.jaridenv.2006.02.015

EMBRAPA - Empresa Brasileira de Pesquisa Agropecuária. Centro Nacional de Pesquisa de Solos. Sistema brasileiro de classificação de solos. 3 ed. Rio de Janeiro: Centro Nacional de Pesquisa de Solos, 2013. 353p.

FERREIRA, D. F. Sisvar: a guide for its bootstrap procedures in multiple comparisons. 
Ciência e Agrotecnologia, v. 38, n. 2, p. 109112, 2014. http://dx.doi.org/10.1590/S141370542014000200001

KÖPPEN, W.; GEIGER, R.Klimate der Erde. Gotha: Verlag Justus Perthes. Wallmap $150 \mathrm{~cm} x 200 \mathrm{~cm} .1928$.

MARCON, M.; MARIANO, K.; BRAGA, R. A.; PAGLIS, C. M.; SCALCO, M. S.; HORGAN, G. W. Estimation of total leaf area in perennial plants using image analysis.Revista Brasileira de Engenharia Agrícola e Ambiental, v. 15, n. 1, p. 96-101, 2011.http://dx.doi.org/10.1590/S141543662011000100014

MARQUES, O. F. C.; GOMES, L. S. P.; MOURTHÉ, M. H. F.; BRAZ, T. H. S.; PIRES NETO, O. S. Palma forrageira: cultivo e utilização na alimentação de bovinos. Cadernos de CiênciasAgrárias,v. 9, n. 1, p. 75-93, 2017.

NEDER, D. G.; COSTA, F. R. da; EDVAN, R. L.; SOUTO FILHO, L. T. Correlations and path analysis of morphological and yield traits of cactus pear accessions. Crop Breeding and Applied Biotechnology, v. 13, n. 3, p. 203207, 2013. http://dx.doi.org/10.1590/S198470332013000300009

OLIVEIRA JUNIOR, S. de; BARREIRO NETO, M.; RAMOS, J. P. de F.; LEITE, M. L. de M. V.; BRITO, E. A. de; NASCIMENTO, J. P. do. Crescimento vegetativo da palam forrageira (Opuntia fícus-indica) em função do espaçamento no Semiárido paraibano. Revista Tecnologia e Ciência Agropecuária, v. 3, n. 1, p. 7-12, 2009.

OLIVEIRA, F. T. de; SOUTO, J. S.; SILVA, R. P. da; ANDRADE FILHO, F. C. de; PEREIRA JUNIOR, E. B. Palma forrageira: adaptação e importância para os ecossistemas áridos e semiáridos. Revista Verde de Agroecologia e Desenvolvimento Sustentável, v. 5, n. 4, p. 27-37, 2010.

OLIVEIRA, R. A. de; DAROS, E.; ZAMBON, J. L. C.; WEBER, H.; IDO, O. T.;
BESPALHOK FILHO, J. C.; ZUFFELLATORIBAS, K. C.; SILVA, D. K. T. da. Área foliar em três cultivares de cana-de-açúcar e sua correlação com a produção de biomassa. Pesquisa Agropecuária Tropical, v. 37, n. 2, p. 71-76, 2007.

PADILHA JUNIOR, M. C.; DONATO, S. L. R.; SILVA, J. A.; DONATO, P. E. R.; SOUZA, E. S. Características morfométricas e rendimento da palma forrageira 'Gigante' sob diferentes adubações e configurações de plantio. Revista Verde de Agroecologia e Desenvolvimento Sustentável, v. 11, n. 1, p. 67-72, 2016. https://doi.org/10.18378/rvads.v11i1.3710

PEDUZZI, A.; WYNNE, R. H.; FOX, T. R.; NELSONM, R. F.; THOMAS, V. A. Estimating leaf area index in intensively managed pine plantations using airborne laser scanner data. Forest Ecology and Management, v. 270, n. 15, p. 54-65, 2012.https://doi.org/10.1016/j.foreco.2011.12. 048.

PINHEIRO, K. M.; SILVA, T. G. F. da.; CARVALHO, H. F. S.; SANTOS, J. E. O.; MORAIS, J. E. F. de.; SÉRGIO ZOLNIER, S.; SANTOS, D. C. dos. Correlações do índice de área do cladódio com características morfogênicas e produtivas da palma forrageira. Pesquisa Agropecuária Brasileira, v. 49, n. 12, p. 939-947, 2014. http://dx.doi.org/10.1590/S0100-

204X2014001200004

ROCHA, R. S.; VOLTOLINI, T. V.; GAVA, C. A. T. Características produtivas e estruturais de genótipos de palma forrageira irrigada em diferentes intervalos de corte. Archivos de Zootecnia, v. 66, n. 255, p. 365373, 2017.

SALES, A. T.; LEITE, M. L. M. V.; ALVES, A. Q.; RAMOS, J. P. F.; NASCIMENTO, J. P. Crescimento vegetativo de palma forrageira em diferentes densidades de plantio no Curimataú Paraibano. Revista Tecnologia e Ciência Agropecuária, v. 7, n. 1, p. 19-24, 2013. 
SANTOS, D. C. dos; FARIAS, I.; LIRA, M. de A.; SANTOS, M. V. F. dos; ARRUDA, G. P. de; COELHO, R. S. B.; DIAS, F. M.; MELO, J. N. de. Manejo e utilização da palma forrageira (Opuntia e Nopalea) em Pernambuco. n. 30. Recife: IPA, 2006. 48 p.

SEBRAE - RN. Palma forrageira e adensada e irrigada. 2010. Disponível em: http://www.ecodebate.com.br/2014/06/03/pal ma-forrageira-um-adensamentoprovidencialartigo-de-joao-suassuna/. Acesso em 10 março de 2017.

SILVA, N. G. de M.; LIRA, M. de A.; SANTOS, M. V. F. dos; DUBEUX JÚNIOR, J. C. B.; MELLO, A. C. L. de; SILVA, M. da C. Relação entre características morfológicas e produtivas de clones de palma forrageira. Revista Brasileira de Zootecnia, v. 39, v. 11, p. 2389-2397, 2010. http://dx.doi.org/10.1590/S1516-

35982010001100011

SILVA, P. F.; MATOS, R. M.; BORGES, V. B.; DANTAS NETO, J.; FARIAS, M. S. S. Morphology and biomass yield of forage cactus under mineral fertilization in organic soil.

AfricanJournalofAgriculturalResearch. v. 11, n. 37, p. 3497-3505, 2016. 10.5897/AJAR2016.11420

SILVA, T. G. F.; MIRANDA, K. R.; SANTOS, D. C.; QUEIROZ, M. G.; SILVA, M. C.; NETO, J. F. C.; ARAÚJO, J. E. M. Área do cladódio de clones de palma forrageira: modelagem, análise e aplicabilidade. Revista Brasileira de Ciências Agrárias, v. 9, n. 4, p. 633-641, 2014. 10.5039/agraria. v9i4a4553

SILVA, T. G. F.; PRIMO J. T. A.; MORAIS, J. E. F.; DINIZ, W. J. S.; SOUZA, C. A. A.; SILVA, M. C. Crescimento e produtividade de clones de palma forrageira no semiárido e relações com variáveis meteorológicas. Revista Caatinga, v. 28, n. 2, p. 10-18, 2015.

SOUZA, M. S.; ALVES, S. S. V.; DOMBROSKI, J. L. D.; FREITAS, J. D. B.; AROUCHA, E. M. M. Comparação de métodos de mensuração de área foliar para a cultura da melancia. Pesquisa Agropecuaria Tropical, v. 42, n. 2, p. 241-245. 2012.

SUASSUNA, P. Lucratividade da Cultura da Palma Forrageira na Paraíba. Disponível em:< www.joaosuassuna.hpg.ig.com.br/sistprod.htm - 5k ->. Acesso em 24 de julho de 2015. 1993.

ZEGBE, J. A.; PÉREZ, A. S.; COVARRUBIAS, J. M. Mineral nutrition enhances yield and affects fruit quality of 'Cristalina' cactus pear. ScientiaHorticulturae, v. 167, n. 6, p. 63-70, 2014.

https://doi.org/10.1016/j.scienta.2013.12.023 